\title{
Dual Treatment Strategy by Venous Ulcers: Pilot Study to Dual-Frequency Ultrasound Application
}

\author{
Ilja Kruglikov, Ekaterina Kruglikova \\ WELLCOMET GmbH, Karlsruhe, Deutschland. \\ E-mail: kruglikov@wellcomet.de \\ Received August 24 $4^{\text {th }}$, 2011; revised October $1^{\text {st }}, 2011$; accepted October $11^{\text {th }}, 2011$.
}

\begin{abstract}
We propose a new dual treatment strategy for venous ulcer, consisting in simultaneous modulation of matrix metalloproteinases (MMPs) and heat shock proteins (HSPs) in the wound. One treatment method which can efficiently modulate both these substances is based on the application of dual-frequency ultrasound (LDM). This strategy was checked in a pilot study on 10 patients with chronic venous ulcers and demonstrated excellent healing rate.
\end{abstract}

Keywords: Venous Ulcer, Dual-Frequency Ultrasound, Matrix Metalloproteinases, Heat Shock Proteins

\section{Introduction}

Chronic wounds (CWs) are the wounds which show no healing tendency during the first 12 weeks of the treatment or do not heal in 12 months. CWs belong to the worldwide most severe health problems not only because of their broad therapy resistance but rather because of permanently increasing costs for the healthcare. Such wounds are usually associated with some severe diseases (e.g. diabetes) and heal very slow even under optimal treatment conditions.

CWs can be subdivided into three groups: pressure sores, diabetic and venous ulcers (the last represents up to $84 \%$ of leg ulcers). Although these wounds have different pathophysiology their healing shows some similar features: local inflammation, building-up of granulation tissue, re-epithelisation of the wound and remodeling of extracellular matrix. These processes are tightly connected with collagen turnover as well as with a shifting of the equilibrium between the processes of production (controlled by mesenchymal cells) and decomposition (controlled primarily by different enzymes from the family of matrix metalloproteinases-MMPs) in the involved connective tissue.

Different theories were developed to explain the pathophysiology of CWs, especially of diabetic and venous ulcers; among them the "fibrin cuff hypothesis" [1], "white cell trapping hypothesis" [2] as well as some others. No of these theories could really explain the difference between normal wounds and CWs.
Recently two new ideas were proposed. One is based on the over-expression of MMPs in the wound bed (see e.g. [3-5]), another is connected with the under-expression of heat shock proteins (HSPs) in the wound under some attendant circumstances [6-9]. Several treatment strategies based on these theories were developed during the last years, among them the local suppression of the MMPs-production through application of the MMP-antagonists as well as the local production of the HSPs in the wound.

Presently the MMP- and HSP-theories exist separately of each other and consequently the corresponding treatment strategies for MMP-suppression do not take into account the HSP-production in the wound and vice versa. Different treatment methods based on these theories demonstrate more or less good healing by some patients but show also a significant group of therapy resistant patients. This means the single treatment strategy may be sub-optimal and has to be replaced through the dualstrategy which takes into account both the processes of MMP- and HSP-production within a CW.

\section{MMPs in Wound Healing}

Different MMPs as well as their antagonists (TIMPs) are believed to be involved in the wound healing processes [4,5]. Initially it was strongly believed that MMPs in the wound are active only during the resolution phase, mainly during the scar resorption. The newest results show however that these enzymes are also active during the inflammation and re-epithelisation phases [5], which 
changes the pathophysiological situation dramatically. The significantly increased activities of MMP-1 (collagenase-1) and MMP-3 (stromelysin-1) were measured in basal keratinocytes and dermal fibroblasts of the wound; very high levels of MMP-2 (gelatinase A) were registered in the wound bed. Such an increase of MMPs activities in the early phases of wound healing can be explained from the physiological point of view. In a normal situation cells are imbedded into relatively compact connective tissue which mechanically restrains their differentiation and mobility. The early activation of the MMPs in the wound healing is needful to "release" them.

If the activity of MMPs in the wound is pathologically high over a long time, a CW can arise, because these enzymes will automatically degrade the newly produced matrix structures. Especially negative can be the long-lasting effect of high concentrated gelatinases-these enzymes destroy inter alia the collagen IV structures which dominate a basal membrane. The activities of MMP-2 and MMP-9 are significantly higher in a CW as in a normal wound and the concentration of MMP-9 in the wound can be even used for prognosis of the healing process [10]. MMPs activities are extremely high by patients with diabetes; concentrations of MMP-1, MMP-2 and MMP-9 in a diabetic wound are manifold higher as in normal traumatic wound [11]. It may be at least partly explained by the fact that high glucose content can stimulate MMP-2 (but not MMP-9) production and at the same time inhibit TIMP-2 [12].

These results show the way to the new treatment strategy based on the MMP-hypothesis. Pathological activities of some important MMPs in CW have to be significantly reduced during some critical recovering time which generally can be estimated as several days. Such suppression can be realized through some pharmacological compounds or through some physical applications.

\section{HSPs in Wound Healing}

Another important aspect of wound healing is the correct protein quality control in the wound. This control will be essentially realized through the HSPs which are involved in cell protection. These molecules are normally responsible for the refolding of the misfolded proteins and degradation of unstable proteins. Insufficient HSPs production can be the reason for the lost of protein control in the tissue and even for some abnormalities and apoptosis $[13,14]$.

Production of Hsp72 in injured tissue is normally strongly activated and looks to be important for the correct wound healing [6,15]. It is actually believed that Hsp72 controls the refolding as well as transport of fresh synthesized proteins and its production is essential for the proper wound healing. Hsp72-production in normal healing wounds is strongly activated, but in CWs it remains suppressed [16]. It was demonstrated that strongly suppressed HSP-production by some diseases (e.g. diabetes) highly correlates with delayed wound healing [7-9]. Patients with type 2 diabetes have reduced gene expression of Hsp72, which correlates with reduced insulin sensitivity [17]. At the same time it was shown that the induction of Hsp72 in cutaneous wounds through e.g. UV-irradiation [18], laser-stimulation [19] as well as after bimoclomol application [20] can accelerate the wound healing.

Treatment strategy based on the HSP-hypothesis has to be capable to stimulate the HSP-production locally in the wound. This stimulation of the HSP-activity can be reached with different pharmacological and physical agents and its result has to be relatively long-lasting. Because of this not only the nature of the applied stimulation but even more the art of the treatment and the selected parameters could be of primary importance.

\section{Are the Single Strategies by CWs Sub-Optimal?}

As it was mentioned above some MMPs are over-expressed and some HSPs are strongly suppressed in CWs which looks to be the typical situation at least by diabetes patients. Simultaneous normalization of both MMPs and HSPs in the wound looks to be important for the proper wound healing. Thus the optimal treatment way looks to be the local suppression of MMPs-activity as well as the local stimulation of the HSP-production in one procedure. The problem is however, that the optimal selected suppression of some MMPs in the wound does not necessarily coincide with the optimal strategy of HSP-stimulation. The well known example is the heating: being one of the optimal ways for HSP-stimulation, heating can also stimulate the MMP-production which would be contra-productive for the wound healing.

In this sense the optimal treatment strategy of CWs has to be considered as a dual treatment strategy. This procedure must additionally have optimal schedule to clamp the reached values of MMPs and HSPs for some minimal time to give the affected tissue the possibility to recover.

If the dual hypothesis is correct then some classical treatment methods which are known to be more or less effective by CWs have to demonstrate modification of both MMPs and HSPs. Let us consider two examples.

\subsection{Compression Therapy}

High compression bandaging (HCB) is effective treatment which is widely used in the wound healing of new venous leg ulcers. It heals almost all new ulcers (less than 6 months' duration) during one year. Can compression inhibit the MMP- and simultaneously stimulate the 
HSP-production? HP can indeed strongly inhibit the production of MMP-2 in the tissue. At the same time it can induce the MMP-9 activity which property can be used e.g. by treatment of hypertrophic scars [21]. To reach a proper MMP-modification with this treatment method it is however important which pressure values and treatment times are used. While we do not know any publication concerning the HSP-production in the wound after HCB, it is indeed known that fibroblasts can respond to compression with induction of Hsp70 [22]. This indirectly supports the dual hypothesis, however it has to be taken into account that some parameter conditions has to be fulfilled which maybe not always the case in the practice.

\subsection{Ultrasound}

There are many reports about the application of ultrasound (US) by CWs. Both low frequency $(20-120 \mathrm{kHz})$ as well as high frequency US waves $(1-4 \mathrm{MHz})$ were applied [23] and demonstrated generally a significant improvement of the wound state but also a significant group of resistant patients. Application of $30 \mathrm{kHz}$ US with intensity of $0.1 \mathrm{~W} / \mathrm{cm}^{2}$ for 10 min three times a week during 8 weeks has demonstrated the $41 \%$ decrease of the ulceration area comparing to $11 \%$ in corresponding control group [24]. Application of $43 \mathrm{kHz}$ US with intensity of $0.6 \mathrm{~W} / \mathrm{cm}^{2}$ for 8 min five times a week for two weeks decreased the full granulation of the wound by $50 \%$ of patients.

High frequency US is usually applied in the form of 1 and $3 \mathrm{MHz}$ ultrasound waves with intensities of 0.1 to $1.0 \mathrm{~W} / \mathrm{cm}^{2}$. The results are contradictive. Some studies demonstrated a good improvement of the wound, e.g. by application of $3 \mathrm{MHz}$ US $\left(1.0 \mathrm{~W} / \mathrm{cm}^{2}\right.$, pulsed 1:4, three times a week for 4 weeks) [25] or under similar conditions [26], other were not able to demonstrate significant healing over placebo by application of $1 \mathrm{MHz}$ US $(0.5$ $\mathrm{W} / \mathrm{cm}^{2}$, pulsed 1:9, three times a week for four weeks) [27]. Also the newest controlled study didn't show any effect of $1 \mathrm{MHz}$ US $\left(0.5 \mathrm{~W} / \mathrm{cm}^{2}\right.$, pulsed 1:4, one time a week for up to 12 weeks) on the healing of venous leg ulcers [28]. Interestingly, the applied frequencies of 1 and $3 \mathrm{MHz}$ were differentiated only according to the penetration depth of US waves. So it was proposed to use the $3 \mathrm{MHz}$ US for treatment of superficial venous ulcers and $1 \mathrm{MHz}$ or less US for the treatment of deep wounds [29].

US can under specific conditions reduce the MMP-activity in the tissue or activate some TIMPs, e.g. TIMP-2 which is an antagonist of MMP-2 (see e.g. [30]). Our in vitro experiments with HL-60 cells (to be published) have shown that ultrasound of different frequencies and intensities can either stimulate (over 100\%) or suppress (up to $60 \%$ ) the production of different MMPs, which makes the parameter selection for the optimal treatment of primary importance.

At the same time, as we have shown recently, specific US stimulation can increase HSP-production tremendously [31]. Also in this case the applied frequency and intensity are of the main importance: treatment with US of $1 \mathrm{MHz}$ shows no HSP-stimulation, treatment with US of $3 \mathrm{MHz}$ frequency increases Hsp72-activity 8-fold but this effect disappears after 24 hours. After application of $10 \mathrm{MHz}$ US as well as of dual ultrasound waves (LDM) of 3 and $10 \mathrm{MHz}$ the Hsp72-activity in HL-60 cells could be increased 15 - 18-fold comparing to control values. The HSP-activity was then reduced to the half of this maximum value after 24 hours. Thus to retain the constant high level of HSP in the wound one has to suppose, such treatments have to be conducted regularly at least once per day.

However the choice of the false frequency can dramatically reduce the treatment effectiveness, because either MMPs or HSPs will be regulated improperly. If HSP modulation is of essential significance for effective CW treatment this could explain the different results by application of $1 \mathrm{MHz}$ and $3 \mathrm{MHz}$ US and make the application of higher US frequencies even more interesting.

One potential candidate for such treatment may be the application of the dual waves which combine two different US waves of different frequencies in one beam. Such an idea was already realized in anti-aging treatments [32].

\section{Main Treatment Idea}

Effectiveness of the CWs treatment can be improved through application of the dual strategy: inhibition of some MMPs as well as stimulation of some HSPs in the wound.

Because the known modulation effects of single treatment on MMPs and HSPs are not very long-lasting and can disappear already after several hours the treatment schedule is extremely important for the optimal wound healing. Typical effective time for the restoration of MMP- and HSP-values after one treatment is between several hours and app. 1 day. The concrete value is very dependent on the treatment peculiarities. To clamp these modified MMP- and HSP-values on the needed level and so to give tissue possibility to recover a special therapy schedule could be needed-daily or even twice per day. Such a therapy schedule is unusual for such treatments and can be called super-fractionation.

\section{Local Dynamical Micro-Massage (LDM $\left.{ }^{\circledR}\right)$}

Application of high frequency ultrasound was till now restricted to standard physiotherapy US waves with sin- 
gle frequencies of 1 and $3 \mathrm{MHz}$, which have the halfpenetration depth in the body of app. 3 and $1 \mathrm{~cm}$, respectively. Alternatively one can apply the US of higher frequency (e.g. $10 \mathrm{MHz}$ ) with a half-penetration depth less than $0.3 \mathrm{~cm}$, which was shown to be able to modulate significantly MMPs and stimulate some HSPs [31], or to use the dual-frequency application, which is currently extensively studied in connection with possible applications in sonodynamic therapy.

The dual-frequency LDM $^{\circledR}$ (Local Dynamical Micro-massage)-wave is shown in Figure 1. In this wave the frequency is not constant but oscillates between two frequencies ( 1 and $3 \mathrm{MHz}$ or 3 and $10 \mathrm{MHz}$, according to application). Such an oscillation means a very rapid change of the pressure gradients in a treated tissue and thus presents the unique possibility to produce a dynamic modulation of the ultrasound micro-massage effects.

Effective suppression of MMPs and stimulation of HSPs which were demonstrated with $\mathrm{LDM}^{\circledR}$ in preliminary experiments make this procedure the optimal candidate for the realisation of the dual treatment strategy by venous ulceration.

\section{Pilot Study Protocol and Preliminary Treatment Results}

In this pilot study we have tested the dual-frequency US waves with frequencies of 3 and $10 \mathrm{MHz}$. The commercially available machine LDM ${ }^{\circledR}$-MED (Wellcomet, Germany) was used as dual wave generator. The single frequencies in the dual wave were changed every $5 \mathrm{~ms}$ (200 times per second). Ultrasound intensity was controlled by digital ultrasound power meter UPM-DT-10 (Ohmic Instruments Co., USA). The US output intensity was controlled before every treatment session.

\subsection{Participants}

10 patients with chronic venous leg ulcers with long-time medical records ( $>6$ months' duration). All patients had the wound surface $>5 \mathrm{~cm}^{2}$. All study participants received the compression therapy for at least several months. This therapy was abandoned without significant improvement before the patients entered this study. No baseline smear test for bacteriological investigation was done.

\subsection{Interventions}

2 times a week with total number of sessions between 8 and 25 according to the evolution of the clinical picture. One treatment lasted 10 to 20 min per wound site (according to the surface) and had the following parameters: LDM 3/10 MHz, $5 \mathrm{~ms} 3 \mathrm{MHz} / 5 \mathrm{~ms} 10 \mathrm{MHz}$, intensity $0.5 \mathrm{~W} / \mathrm{cm}^{2}$ (the first 4 sessions), then $1.0 \mathrm{~W} / \mathrm{cm}^{2}$. During the treatment the whole wound as well as the surrounding
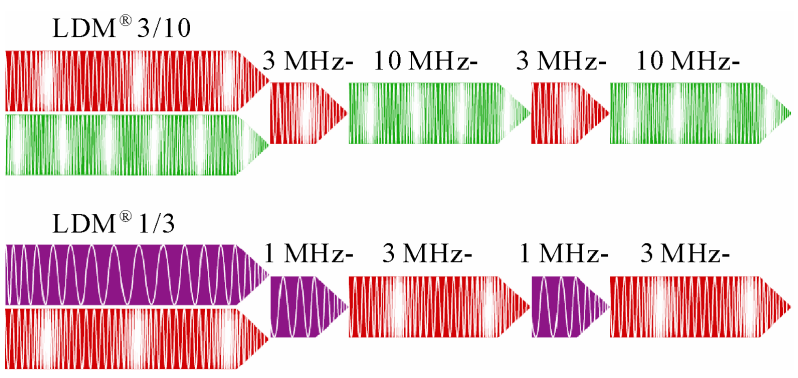

Figure 1. Wave formation in $\mathrm{LDM}^{\circledR \text { plus }}$ technology.

tissue of at least $3 \mathrm{~mm}$ from the wound edge were treated uniformly. Sterilized US gel was used as a coupling medium. In 3 cases with delayed healing we have applied the super-fractionation - the treatments were conducted 2-3 times a day for 3 days. The control investigation was done and documented 3 to 8 weeks after the last treatment.

\subsection{Results}

All patients have shown the intensive wound granulation at least after the second treatment. All treated wounds were fully re-epithelised to the end of the treatment course. The process continued also after finishing the treatment course. The follow-up examination demonstrated the full wound healing.

The treatment was pain free. No side effects were registered. The patients with painful wound showed significant pain reduction of at least 3 levels according to $\mathrm{Nu}-$ merical Rating Skala (NRS) already after 3 - 4 treatments. After finishing the treatment course, all patients were pain free.

Some treatment results are demonstrated in Figures 2-4.

\section{Conclusions}

Small new venous leg ulcers have generally a good healing prognosis and most of them can be closed through application of high compression bandaging within a year [28]. Such a long treatment time reduces significantly the patients' quality of life and tremendously increases the health costs. Big and old venous leg ulcers (with duration over 6 months') have the bad therapy prognosis and cannot be effectively improved in a reasonable time. General decrease of the treatment time as well as increase of the healing rate by patients with poor prognostic profiles has the main priority in the development of new treatment methods [28].

Dual-frequency US (LDM ${ }^{\circledR}$ ) with frequencies of 3 and $10 \mathrm{MHz}$ based on the simultaneous modulation of MMPs and HSPs in the wound looks to be an effective alternative method for direct treatment of venous leg ulceration. In this pilot study we have demonstrated the complete 


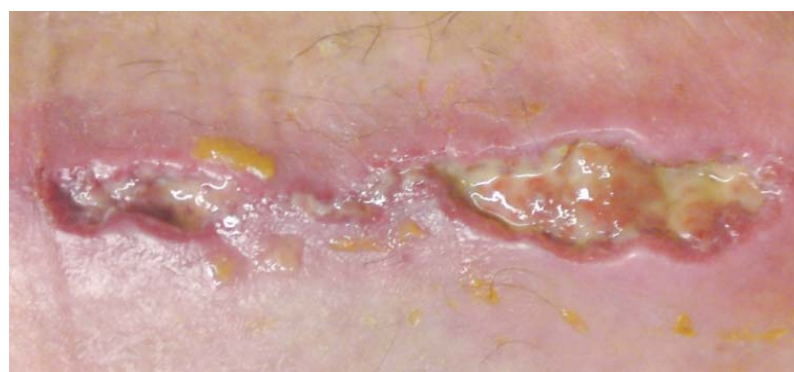

(a)

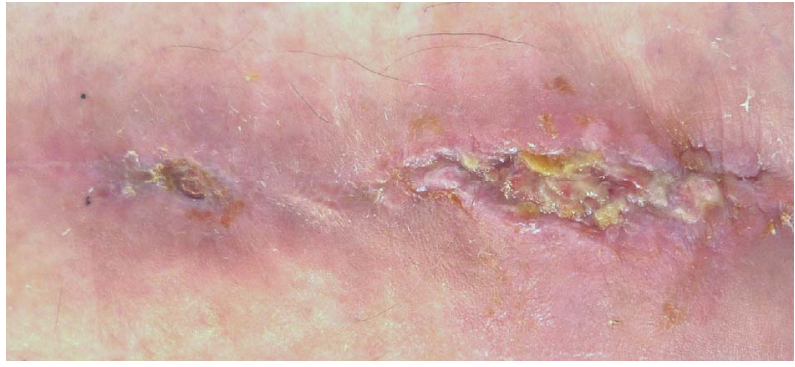

(c)

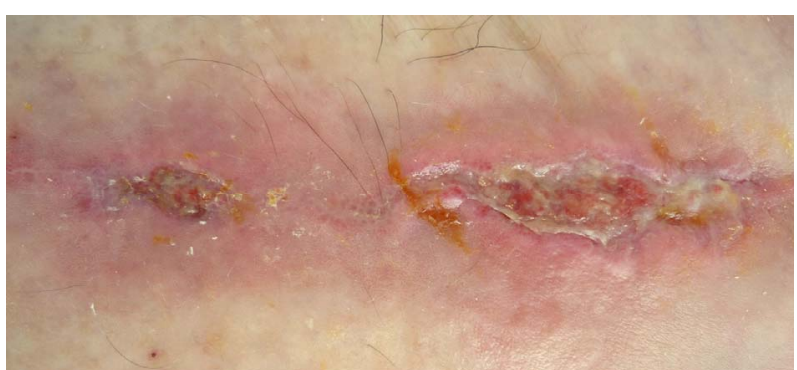

(b)

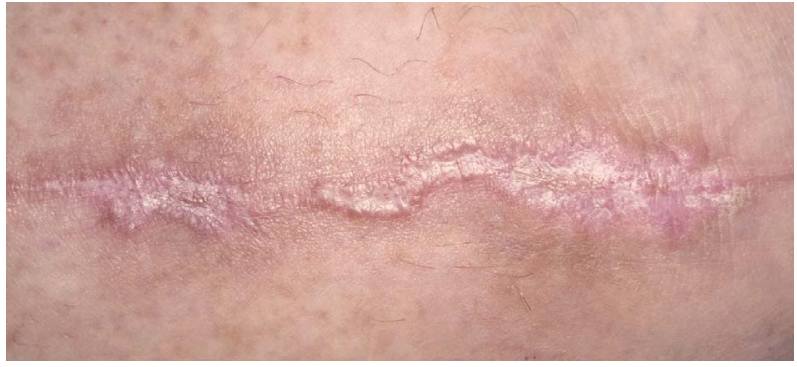

(d)

Figure 2. Chronic venous ulcer after fibula fracture, duration 1.5 years: (a) before; (b) after 15 sessions; (c) after 21 sessions; (d) 10 weeks after 25 sessions.

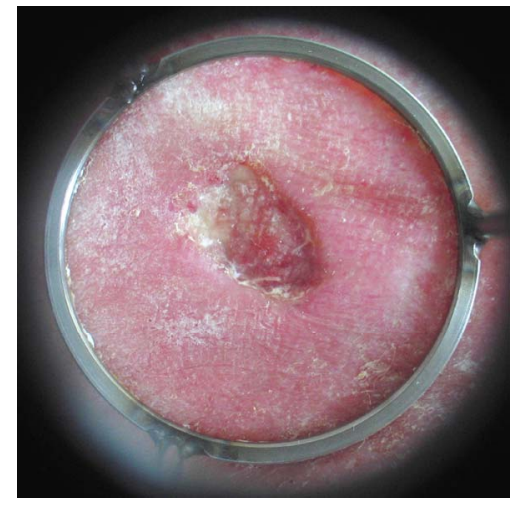

(a)

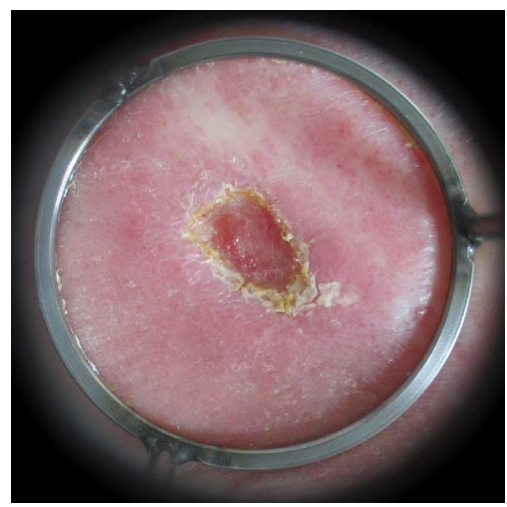

(c)

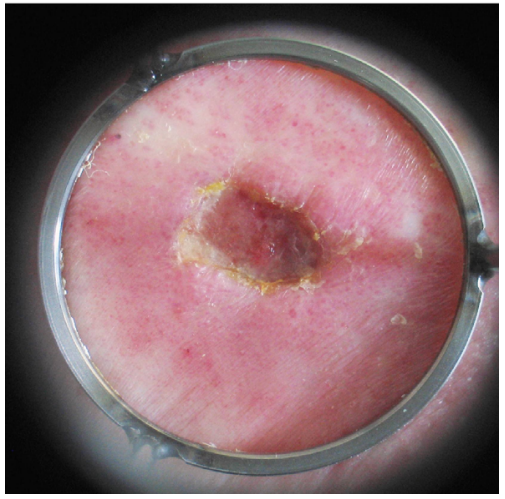

(b)

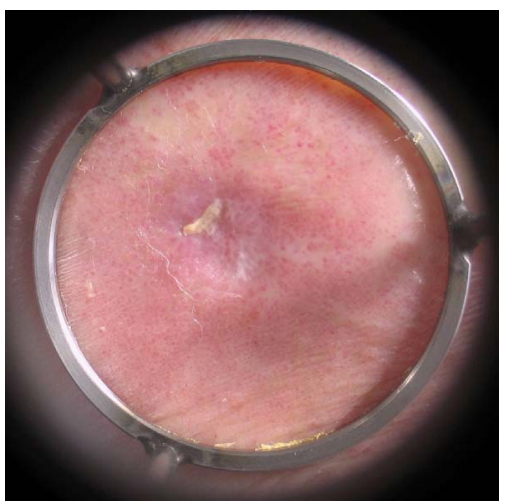

(d)

Figure 3. Chronic venous ulcer, duration 2 years, diabetic foot: (a) before; (b) after 3 sessions; (c) after 6 sessions; (d) 3 weeks after 8 sessions. 


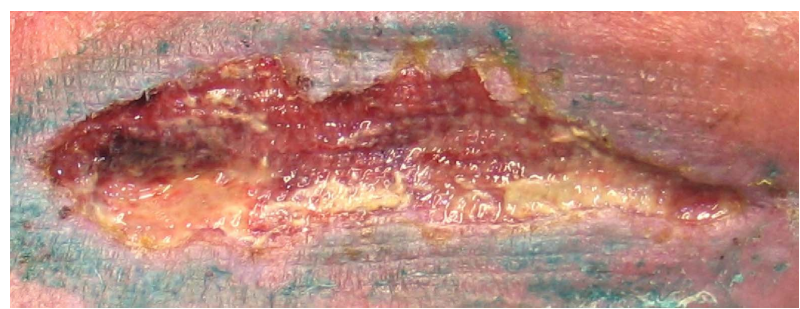

(a)

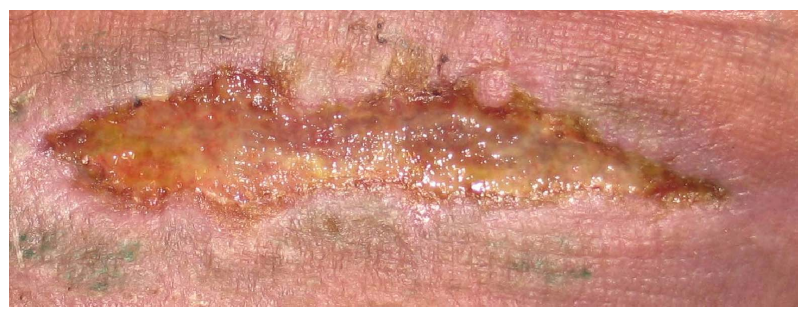

(c)

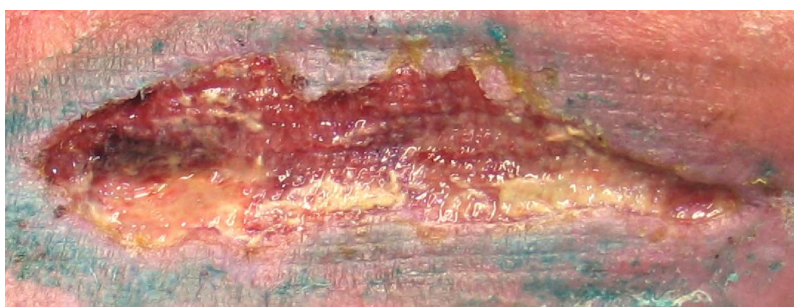

(b)

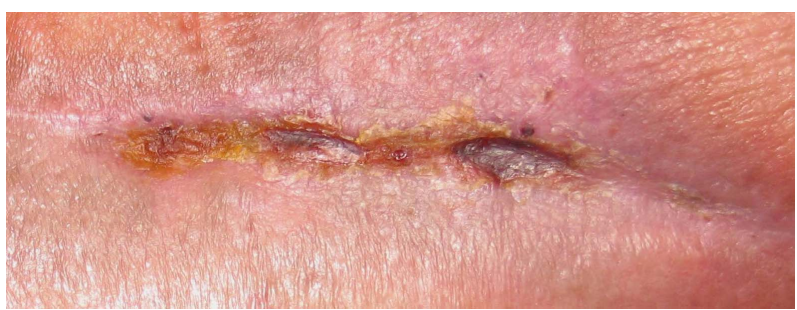

(d)

Figure 4. Chronic venous ulcer after muscle transplantation, duration 2.5 years: (a) before; (b) after 4 sessions; (c) after 10 sessions; (d) 7 weeks after 12 sessions.

healing of ulceration by all ten treated participants independent on the origin, duration and size of the wound. The shortest treatment time was by participant with ulcer of $5 \mathrm{~cm}^{2}$ (duration over 6 years) - 2 sessions (1 week), the longest by participant with ulcer after fibula fracture (over $12 \mathrm{~cm}^{2}$, duration over 1.5 years) - 25 sessions in 10 weeks.

The treatment is pain and side effects free. Because of very rapid improvement of clinical picture this treatment was well accepted by patients.

Although all test persons have shown the full healing of the wound and other investigators has also reported the full healing of venous leg ulcers with this technology (even with duration of 15 and 22 years), the controlled study with more patients is needed to make the strict statistical evaluation.

\section{REFERENCES}

[1] N. L. Browse and K. G. Burnand, "The Cause of Venous Ulceration,” Lancet, Vol. 2, No. 8292, 1982, pp. 243-245. doi:10.1016/S0140-6736(82)90325-7

[2] P. D. Smith, P. Thomas, J. H. Scurr and J. A. Dormandy, "Causes of Venous Ulceration: A New Hypothesis," British Medical Journal, Vol. 296, No. 6638, 1988, pp. 17261727. doi:10.1136/bmj.296.6638.1726

[3] H. Cook, P. Stephens, K. J. Davies, K. G. Harding and D. W. Thomas, "Defective Extracellular Matrix Reorganization by Chronic Wound Fibroblasts is Associated with Alterations in TIMP-1, TIMP-2, and MMP-2 Activity," Journal of Investigative Dermatology, Vol. 115, No. 2, 2000, pp. 225-233. doi:10.1046/j.1523-1747.2000.00044.X

[4] Y. Herouy, "The Role of Matrix Metalloproteinases (MMPs) and Their Inhibitors in Venous Leg Ulcer Healing," Phlebology, No. 44, 2004, pp. 231-243.

[5] S. E. Gill and W. C. Parks, "Metalloproteinases and Their Inhibitors: Regulators of Wound Healing,” International Journal of Biochemistry \& Cell Biology, Vol. 40, No. 6-7, 2008, pp. 1334-1347. doi:10.1016/j.biocel.2007.10.024

[6] A. F. Laplante, V. Moulin, F. A. Auger, J. Landry, H. Li, G. Morrow, R. M. Tanguay and L. Germain, "Expression of Heat Shock Proteins in Mouse Skin during Wound Healing,” Journal of Histochemistry \& Cytochemistry, Vol. 46, No. 11, 1998, pp. 1291-1301. doi:10.1177/002215549804601109

[7] M. S. Bitar, T. Farook, B. John and I. M. Francis, "HeatShock Protein 72/73 and Impaired Wound Healing in Diabetic and Hypercortisolemic States," Surgery, Vol. 125, No. 6, 1999, pp. 594-601. doi:10.1016/S0039-6060(99)70222-9

[8] A. L. McMurtry, K. Cho, L. J. Young, C. F. Nelson and D. G. Greenhalgh, "Expression of HSP70 in Healing Wounds of Diabetic and Nondiabetic Mice,” Journal of Surgical Research, Vol. 86, No. 1, 1999, pp. 36-41. doi:10.1006/jsre.1999.5700

[9] M. Atalay, N. Oksala, J. Lappalainen, D. E. Laaksonen, C. K. Sen and S. Roy, "Heat Shock Proteins in Diabetes and Wound Healing,” Current Protein \& Peptide Science, Vol. 10, No. 1, 2009, pp. 85-95. doi:10.2174/138920309787315202

[10] E. A. Rayment, Z. Upton and G. K. Shooter, "Increased Matrix Metalloproteinase-9 (MMP-9) Activity Observed in Chronic Wound Fluid is Related to the Clinical Severity of the Ulcer," British Journal of Dermatology, Vol. 158, No. 5, 2008, pp. 951-961. doi:10.1111/j.1365-2133.2008.08462.x

[11] R. Lobmann, A. Ambrosch, G. Schultz, K. Waldmann, S. Schiweck and H. Lehnert, "Expression of Matrix-Metal- 
loproteinases and Their Inhibitors in the Wounds of Diabetic and Non-Diabetic Patients,” Diabetologia, Vol. 45, No. 7, 2002, pp. 1011-1016. doi:10.1007/s00125-002-0868-8

[12] F. M. Ho, S. H. Liu, W. W. Lin and C. S. Liau, "Opposite Effects of High Glucose on MMP-2 and TIMP-2 in Human Endothelial Cells,” Journal of Cell Biochemistry, Vol. 101, No. 2, 2007, pp. 442-450. doi:10.1002/jcb.21192

[13] P. Verbeke, J. Fonager, B. F. C. Clark and S. I. S. Rattan, "Heat Shock Response and Ageing: Mechanisms and Applications,” Cell Biololy International, Vol. 25, No. 9, 2001, pp. 845-857. doi:10.1006/cbir.2001.0789

[14] C. Söti, A. S. Sreedhar and P. Csermely, "Apoptosis, Necrosis and Cellular Senescence: Chaperone Occupancy as a Potential Switch,” Aging Cell, Vol. 2, No. 1, 2003, pp. 39-45. doi:10.1046/j.1474-9728.2003.00031.x

[15] S. D. Morris, "Heat Shock Proteins and the Skin," Clinical \& Experimental Dermatology, Vol. 27, No. 3, 2002, pp. 220-224. doi:10.1046/j.1365-2230.2002.01012.x

[16] M. Oberringer, H. P. Baum, V. Jung, C. Welter, J. Frank, M. Kuhlmann, W. Mutschler and R. G. Hanselmann, "Differential Expression of Heat Shock Protein 70 in Well Healing and Chronik Human Wound Tissue,” Biochemical \& Biophysical Research Communications, Vol. 214, No. 3, 1995, pp. 1009-1014. doi:10.1006/bbrc.1995.2386

[17] J. Chung, A.-K. Nguyen, D. C. Henstridge, A. G. Holmes, M. H. S. Chan, J. L. Mesa, G. I. Lancaster, R. J. Southgate, C. R. Bruce, S. J. Duffy, I. Horvath, R. Mestril, M. J. Watt, P. L. Hooper, B. A. Kingwell, L. Vigh, A. Hevener and M. A. Febbario, "HSP72 Protects against ObesityInduced Insulin Resistance,” Proceedings of the National Academy of Sciences, Vol. 105, No. 5, 2008, pp. 17391744. doi:10.1073/pnas.0705799105

[18] M. M. Simon, A. Reikerstorfer, A. Schwarz, C. Krone, T. A. Luger, M. Jäättelä and T. Schwarz, "Heat Shock Protein 70 Overexpression Affects the Response to Ultraviolet Light in Murine Fibroblasts. Evidence for Increased Cell Viability and Suppression of Cytokine Release," Journal of Clinical Investigation, Vol. 95, No. 3, 1995, pp. 926-933. doi:10.1172/JCI117800

[19] E. Souil, A. Capon, S. Mordon, A. T. Dinh-Xuan, B. S. Polla and M. Bachelet, "Treatment with 815-nm Diode Laser Induces Long-Lasting Expression of 72-kDa Heat Shock Protein in Normal Rat Skin,” British Journal of Dermatology, Vol. 144, No. 2, 2001, pp. 260-266. doi:10.1046/j.1365-2133.2001.04010.x

[20] L. Vígh, P. N. Literáti, I. Horváth, Z. Török, G. Balogh, A. Glatz, E. Kovács, I. Boros, P. Ferdinándy, B. Farkas, L. Jaszlits, A. Jednákovits, L. Korányi and B. Maresca, "Bimoclomol: A Nontoxic, Hydroxylamine Derivative with Stress Protein-Inducing Activity and Cytoprotective Effects," Nature Medicine, Vol. 3, No. 10, 1997, pp. 11501154. doi:10.1038/nm1097-1150

[21] F. Reno, P. Grazianetti, M. Stella, G. Magliacani, C.
Pezzuto and M. Cannas, "Release and Activation of Matrix Metalloproteinase-9 during in Vitro Mechanical Compression in Hypertrophic Scars," Archives of Dermatology, Vol. 138, No. 4, 2002, pp. 475-478.

doi:10.1001/archderm.138.4.475

[22] K. Kaarniranta, C. I. Holmberg, M. J. Lammi, J. E. Eriksson, L. Sistonen and H. J. Helminen, "Primary Chondrocytes Resist Hydrostatic Pressure-Induced Stress while Primary Synovial Cells and Fibroblasts Show Modified Hsp70 Response,” Osteoarthritis \& Cartilage, Vol. 9, No. 1, 2001, pp. 7-13. doi:10.1053/joca.2000.0354

[23] C. Uhlemann and U. Wollina, "Wirkungsphysiologische Aspekte des Therapeutischen Ultraschalls in der Wundbehandlung," Phlebologie, Vol. 32, No. 4, 2003, pp. 8185.

[24] M. Weichenthal, P. Mohr, W. Stegman and E. W. Breitbart, "Low-Frequency Ultrasound Treatment of Chronic Venous Ulcers,” Wound Repair \& Regeneration, Vol. 5, No. 1, 1997, pp. 18-22. doi:10.1046/j.1524-475X.1997.50107.X

[25] C. Roche and J. West, "A Controlled Trial Investigating the Effect of Ultrasound on Venous Ulcers Referred from General Practitioners,” Physiotherapy, Vol. 70, No. 12, 1984, pp. 475-477.

[26] M. J. Callam, D. R. Harper and J. J. Dale, “A Controlled Trial of Weekly Ultrasound Therapy in Chronic Leg Ulceration,” Lancet, Vol. 330, No. 8852, 1987, pp. 204-206. doi:10.1016/S0140-6736(87)90776-8

[27] T. Lundberg, F. Nordstrum, G. Brodda-Jansen, S. V. Ericsson, J. Kjartansson and U. E. Samuelson, "Pulsed Ultrasound does Not Improve Healing of Venous Ulcers," Scandinavian Journal of Rehabilitation Medicine, Vol. 22, No. 4, 1990, pp. 195-197.

[28] J. M. Watson, A. R. Kang'ombe, M. O. Soares, L.-H. Chuang, G. Worthy, J. M. Bland, C. Iglesias, N. Cullum, D. Torgerson and E. A. Nelson, "Use of Weekly, Low Dose, High Frequency Ultrasound for Hard to Heal Venous Leg Ulcers: The VenUS III Randomised Controlled Trial,” British Medical Journal, Vol. 342, 2011, p. d1092. doi:10.1136/bmj.d1092

[29] J. Hart, "The Use of Ultrasound Therapy in Wound Healing,” Journal of Wound Care, Vol. 7, No. 1, 1998, pp. 2528.

[30] S. R. Park, B. H. Choi and B.-H. Min, "Low-Intensity Ultrasound (LIUS) as an Innovative Tool for Chondrogenesis of Mesenchymal Stem Cells (MSCs),” Organogenesis, Vol. 3, No. 2, 2007, pp. 74-78.

[31] W. Sontag and I. L. Kruglikov, "Expression of Heat Shock Proteins after Ultrasound Exposure in HL-60 Cells,” Ultrasound in Medicine \& Biology, Vol. 35, No. 6, 2009, pp. 1032-1041. doi:10.1016/j.ultrasmedbio.2008.12.011

[32] I. L. Kruglikov and W. Sontag, "Ultrasound of $10 \mathrm{MHz}$ Frequency as a Novel Strategy for Skin Anti-Aging Therapy,” Medical Hypotheses, Vol. 74, No. 3, 2010, pp. 620621. doi:10.1016/j.mehy.2009.10.048 